\title{
Amano K, Hori T, Kawamata T, Okada Y (2016) Repair and prevention of cerebrospinal fluid leakage in transphenoidal surgery: a sphenoid mucosa technique. Neurosurg Rev. 39: 123-131
}

\author{
Atul Goel ${ }^{1}$ \\ Received: 3 April 2016 / Accepted: 16 August 2016/Published online: 27 August 2016 \\ (C) Springer-Verlag Berlin Heidelberg 2016
}

Keywords Mucosal flap $\cdot$ Pituitary tumor $\cdot$ Reconstruction

Sir,

We read the above-referenced article by Amano et al. [1]. The authors have discussed the use of sphenoid sinus mucosa either as a free flap or as a vascularized pedicled flap for reconstruction of the meningeal defects created following surgery for pituitary tumors. It is indeed surprising that the authors have not found my article on their literature search that discusses the technique of use of sphenoid sinus mucosal flaps for reconstruction after transsphenoidal surgery for pituitary tumors [2]. My article has been published in a prominent journal and is available in all major search indices. I wish that the authors acknowledge this misrepresentation of facts that has the potential of affecting future publications that can be based on this article.

\section{References}

1. Amano K, Hori T, Kawamata T, Okada Y (2016) Repair and prevention of cerebrospinal fluid leakage in transphenoidal surgery: a sphenoid mucosa technique. Neurosurg Rev 39:123-131

2. Goel A, Muzumdar DP (2003) Reconstruction of the Sella floor using vascularized pedicled mucosal flap. Br J Neurosurg 17(6): 553-555

Atul Goel

atulgoel62@hotmail.com

1 Department of Neurosurgery, King Edward VII Memorial Hospital and Seth G.S. Medical College, Parel, Mumbai 400012, India 